\title{
IMPLEMENTASI KRIPTOGRAFI DENGAN METODE ELLIPTIC CURVE CRYPTOGRAPHY (ECC) UNTUK APLIKASI CHATTING BERBASIS ANDROID
}

\author{
Ainur Rilo Taqwa ${ }^{1)}$, Danang Haryo Sulaksono ${ }^{2)}$ \\ ${ }^{1,2}$ Jurusan Teknik Informatika, Fakultas Teknik Elektro dan Teknologi Informasi \\ Institut Teknologi Adhi tama Surabaya \\ email : ainurrilo@ymail.com, danang_h_s@itats.ac.id
}

\begin{abstract}
Information dissemination facilities in the current technological era can be done quickly and easily through the android application media. One of the most frequently used media for information dissemination is chatting. The problem with this research is that the chat application allows someone to send messages or files to other users who have access rights, with the risk that the data will be seen by anyone who has access rights in it. This can happen because in the chat application can see anything that is shared as long as you have access rights, but sometimes there is some data that is privacy. So it is necessary to add a means to secure this privacy data so it cannot be seen by other users. The solution to overcome this problem is a cryptographic system. One cryptographic method that provides solutions to information security problems is the Elliptic Curve Cryptography (ECC) method. In this paper, an online system in order to implement cryptography with the Elliptic Curve Cryptography (ECC) method for Android-based chat applications. The testing process in this study using 25 image data obtained, obtained an average avalanche effect value of 79,8881925. The average avalanche effect that produces a large enough percentage proves that the application is running well, because the greater the percentage obtained, the better the application is running. From the above test it can be concluded that the Elliptic Curve Cryptography (ECC) algorithm method is effective for hiding data files in chat applications that are privacy.
\end{abstract}

\begin{tabular}{|c|c|}
\hline Article History & ABSTRAK \\
\hline Received 2020-09-25 & \multirow{5}{*}{$\begin{array}{l}\text { Fasilitas penyebaran informasi pada era teknologi yang saat ini dapat dilakukan } \\
\text { dengan cepat dan mudah melalui media aplikasi android. Salah satu media yang } \\
\text { paling sering digunakan untuk penyebaran informasi adalah chatting. Masalah dari } \\
\text { penelitian ini adalah aplikasi chatting memungkinkan seseorang dapat mengirim } \\
\text { pesan ataupun file kepada user lain yang telah memiliki hak akses, dengan resiko } \\
\text { datanya akan dapat dilihat oleh siapa saja yang memiliki hak akses didalamnya. Hal } \\
\text { ini dapat terjadi karena didalam aplikasi chatting tersebut dapat melihat apapun yang } \\
\text { dibagi selama memiliki hak akses, namun terkadang ada beberapa data yang bersifat } \\
\text { privasi. Sehingga perlu ditambahkan suatu sarana untuk mengamankan data privasi } \\
\text { ini agar tidak dapat dilihat oleh user lain. Adapun solusi untuk mengatasi hal tersebut } \\
\text { maka dibuatlah sebuah sistem kriptografi. Salah satu metode kriptografi yang } \\
\text { memberikan solusi untuk permasalahan keamanan informasi adalah metode Elliptic } \\
\text { Curve Cryptography (ECC). Pada paper ini, dibangun sebuah sistem online agar } \\
\text { dapat mengimplementasikan cryptography dengan metode Elliptic Curve } \\
\text { Cryptography (ECC) untuk aplikasi chatting berbasis Android. Proses pengujian } \\
\text { pada penelitian ini menggunakan } 25 \text { data citra didapatkan, didapatkan nilai } \\
\text { avalanche effect rata - rata sebesar } 79,8881925 \text {. Nilai rata - rata avalanche effect } \\
\text { yang menghasilkan persentase yang cukup besar membuktikan bahwa aplikasi } \\
\text { berjalan dengan baik, karena semakin besar persentase yang didapatkan maka } \\
\text { semakin baik aplikasi itu berjalan. Dari pengujian diatas dapat disimpulkan bahwa } \\
\text { metode algoritma Elliptic Curve Cryptography (ECC) ini efektif untuk } \\
\text { menyembunyikan file data pada aplikasi chatting yang bersifat privasi. }\end{array}$} \\
\hline 2020-07-20 & \\
\hline Accepted 2020-11-04 & \\
\hline Key words & \\
\hline $\begin{array}{l}\text { Kriptografi, Algoritma } \\
\text { Elliptic Curve Cryptograph } \\
\text { (ECC), Avalanche Effect }\end{array}$ & \\
\hline
\end{tabular}

\section{PENDAHULUAN}

Fasilitas penyebaran informasi pada era teknologi yang saat ini dapat dilakukan dengan cepat dan mudah melalui media aplikasi android. Salah satu media yang paling sering digunakan untuk penyebaran informasi adalah chatting. Aplikasi chatting merupakan suatu sarana untuk berkomunikasi langsung sesama pengguna internet. Aplikasi chatting saat ini tidak hanya terbatas berupa data teks tapi juga berupa gambar (image). (Khadim, 2015).

Secara khusus, aplikasi chatting merupakan suatu pesan instant ataupun instant messaging di sebuah teknologi jaringan komputer yang mengijinkan pemakainya untuk mengirimkan pesan ke pengguna lain yang tersambung dalam sebuah jaringan komputer ataupun internet. 
Masalah dari penelitian ini adalah aplikasi chatting memungkinkan seseorang dapat mengirim pesan ataupun file berupa teks dan citra kepada user lain yang telah memiliki hak akses, dengan resiko datanya akan dapat dilihat oleh siapa saja yang memiliki hak akses didalamnya. Hal ini dapat terjadi karena didalam aplikasi chatting tersebut dapat melihat apapun yang dibagi selama memiliki hak akses, namun terkadang ada beberapa data seperti teks dan citra yang bersifat privasi. Sehingga perlu ditambahkan suatu sarana untuk mengamankan data privasi ini agar tidak dapat dilihat oleh user lain.

Adapun solusi untuk mengatasi hal tersebut maka dibuatlah sebuah sistem kriptografi. Salah satu metode kriptografi yang memberikan solusi untuk permasalahan keamanan informasi adalah metode Elliptic Curve Cryptography (ECC). Metode ECC adalah metode kriptografi yang memberikan solusi kunci publik secara independen / bebas.

Berdasarkan latar belakang yang telah dijelaskan sebelumnya, maka dapat dirumuskan permasalahan. Yaitu bagaimana mengimplementasikan cryptography dengan metode Elliptic Curve Cryptography (ECC) untuk aplikasi chatting berbasis android dan bagaimana performa komputasi metode algoritma Elliptic Curve Cryptography (ECC) untuk aplikasi chatting.

Berdasarkan rumusan masalah diatas maka tujuan penelitian ini adalah untuk Menjaga keamanan file data pada aplikasi chatting menggunakan algoritma Elliptic Curve Cryptography (ECC) berbasis android. Dan Menyembunyikan file data pada aplikasi chatting yang bersifat privasi menggunakan algoritma Elliptic Curve Cryptography (ECC). Manfaat yang didapatkan pada penelitian ini adalah mengamankan file data online yang bersifat pribadi pada aplikasi chatting.

\section{TINJAUAN PUSTAKA}

\section{Kriptografi}

Kriptografi berasal dari gabungan dua kata yaitu "Crypto" yang berarti rahasia dan "graphy" yang berarti tulisan. Dalam bahasa komputasi kriptografi diartikan sebagai ilmu dan seni untuk menjaga keamanan data. Ahli kriptografi disebut kriptografer. (Jaya, 2017).

\section{Algoritma Elliptic Curve Cryptography (ECC)}

Eliptic Curve Cryptography (ECC) merupakan sistem kriptografi kunci publik yang memanfaatkan persamaan kurva eliptik. Algoritma ini dirancang dan diajukan oleh Neal Koblitz dan Victor S. Miller. Penyebab utamanya adalah karena dengan menggunakan kunci yang jauh lebih kecil atau pendek, Eliptic Curve Cryptography (ECC) tetap dapat memberikan tingkat keamanan yang sama dengan algoritma asimetrik lainnya yang menggunakan kunci yang lebih besar. Dengan ukuran kunci yang lebih kecil dan tingkat keamanan yang sama tinggi, implementasi Eliptic Curve Cryptography (ECC) menjadi lebih efisien. (Edy, 2017).

\section{Arsitektur Platform Android}

Arsitektur lain yang tak kalah penting dalam proses perancangan sistem cloud computing adalah Application Programming Interface (API). Menurut Lew Tucker, Chief Technology Officer dari Sun Microsystems Cloud Computing Division, API merupakan aspek yang seringkali dilupakan oleh para pengguna layanan cloud computing. Aplikasi yang tersedia pada cloud computing dapat diakses melalui Internet.

\section{Java Android}

Java adalah bahasa berorientasi objek yang dapat digunakan untuk pengembangan aplikasi mandiri, aplikasi berbasis internet, serta aplikasi untuk perangkat - perangkat cerdas yang dapat berkomunikasi lewat internet atau jaringan komunikasi. Dalam java ada 2 (dua) jenis program berbeda, yaitu aplikasi dan applet. 


\section{Android SDK (Software Development Kit)}

Andrioid SDK adalah tools API (Application Programing Interface) yang diperlukan untuk memulai mengembangkan aplikasi pada platform Android menggunakan bahasa pemrograman Java.

\section{Pengujian}

Untuk melakukan pengujian pada penelitian ini menggunakan beberapa parameter yang digunakan. Parameter yang digunakan adalah Avalanche Effect. Avalanche Effect adalah salah satu cara untuk mengetahui tingkat efektifitas algoritma kriptografi dari file yang dienkripsi. Dengan ketentuan bahwa algoritma itu semakin baik bila memiliki nilai Avalanche Effect yang tinggi. Avalanche Effect dapat dihitung dengan menggunakan rumus 1.

Avalanche Effect $=\frac{j b t}{j b c} \times 100 \%$

Keterangan:

jbt : Jumlah bit yang terbaikdalam chipertext

jbc : Jumlah bit keseluruhan dalam

\section{METODE}

\section{Gambaran Umum}

Dalam penelitian ini diterapkan sistem menggunakan algoritma Elliptic Curve Cryptography (ECC). Dimana hal ini berguna untuk mengenkripsi dan dekripsi file citra pada saat chatting.

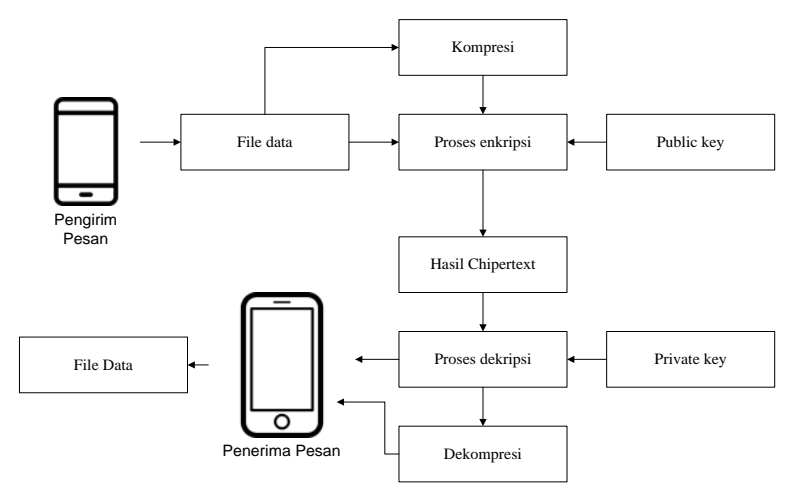

Gambar 1. Skema Perancangan Aplikasi

Gambar 1 diatas menjelaskan tentang skema rancangan aplikasi enkripsi dan dekripsi algoritma Elliptic Curve Cryptography (ECC). Dimana sistem ini berbasis android sehingga untuk menggunakannya perlu menggunakan smartphone. Dimana salah satu komputer akan bertindak sebagai client ataupun server, client sebagai penerima file data. File data yang dikirimkan oleh server harus di enkripsikan terlebih dahulu sebelum dikirim ke client. Dengan demikian meskipun file data terbaca oleh pihak lain yang berusaha membacanya akan sulit untuk memahaminya. Selain harus mendekripsikannya, tentu metode dalam pemecahannyapun hanya akan dipahami oleh client dan server.

\section{Rancangan dan Pembangunan}

Tahap ini menjelaskan tentang prosedur dan proses apa saja yang akan dilakukan oleh aplikasi, alur proses, serta tampilan dasar aplikasi. Alur proses dalam hal ini berbentuk flowchart dan perhitungan manual dari metode yang digunakan. Flowchart dari sistem yang dibangun dapat dilihat pada gambar 3.2. 


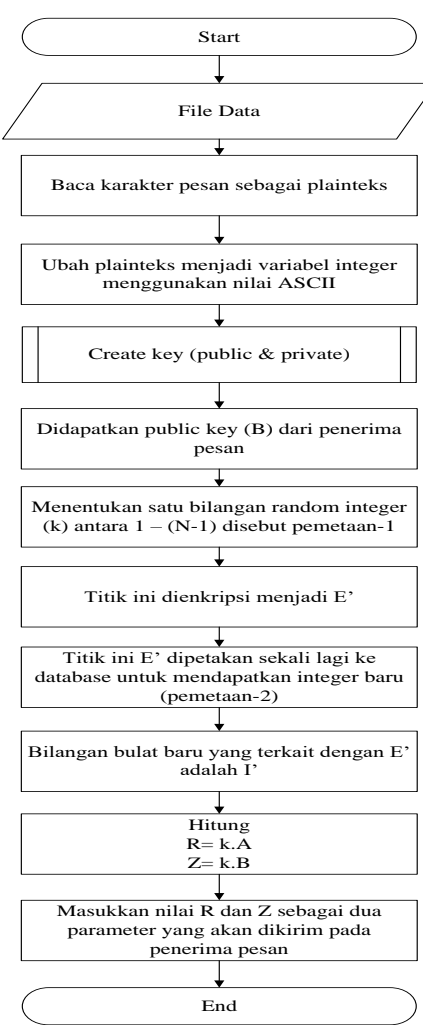

Gambar 2. Flowchart Enkripsi Algoritma ECC

Gambar 2 dibawah menjelaskan tentang alur enkripsi algoritma Elliptic Curve Cryptography (ECC). Proses pertama yang dilakukan adalah dengan menginputkan file data yang akan di enkripsi. Kemudian baca file data sebagai plainteks, untuk diubah menjadi variabel integer menggunakan nilai ASCII. Kemudian lakukan proses create key (public \& private), maka akan didapatkan public key (B) dari penerima pesan. Selanjutnya menentukan satu bilangan random integer (k) antara $1-(\mathrm{N}-1)$ disebut pemetaan-1. Titik yang dipilih tadi selanjutnya dienkripsi menjadi E'. titik ini E' dipetakan sekali lagi ke database untuk mendapatkan integer baru yang disebut pemetaan-2. Lalu bilangan bulat baru yang terkait dengan E' adalah I' didapatkan. Kemudian menghitung nilai $\mathrm{R}$ dengan mengalikan nilai $\mathrm{k}$ dengan A (titik awal). Dan menghitung nilai $\mathrm{Z}$ dengan mengalikan nilai $\mathrm{k}$ dengan $\mathrm{B}$ (public key). Terakhir, masukkan nilai $\mathrm{R}$ dan $\mathrm{Z}$ sebagai dua parameter yang akan dikirim pada penerima pesan.

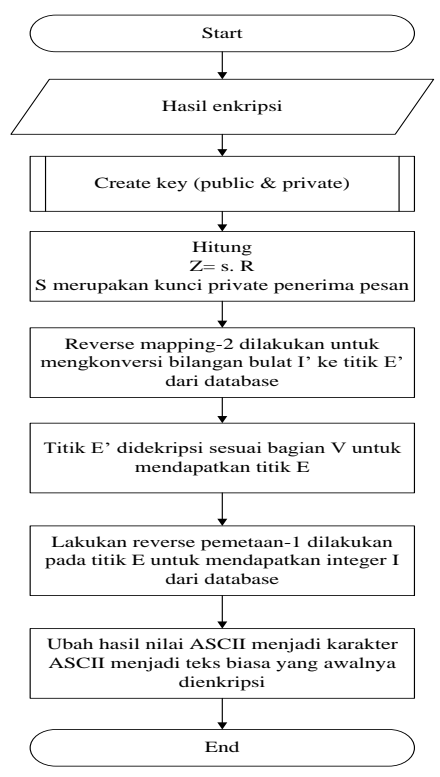

Gambar 3. Flowchart Dekripsi Algoritma ECC 
Gambar 3 dibawah menjelaskan tentang alur dekripsi algoritma Elliptic Curve Cryptography (ECC). Proses pertama yang dilakukan adalah dengan menginputkan hasil enkripsi. Kemudian dilakukan proses create Key (public \& private). Kemudian hitung nilai $\mathrm{Z}$ dengan mengalikan nilai $\mathrm{s}$ dengan $\mathrm{R}$, dimana s adalah kunci private penerima pesan. Selanjutnya dilakukan proses reverse mapping-2 untuk mengkonversi bilangan bulat I' ke titik E' dari database. Lalu, titik E' didekripsikan sesuai bagian V untuk mendapatkan titik E. Setelah itu lakukan reverse pemetaan-1 pada titik E untuk mendapatkan integer I dari database. Kemudian ubah hasil nilai ASCII menjadi karakter ASCII menjadi teks biasa yang awalnya dienkripsi.

Gambar 4. menjelaskan tentang alur create key algoritma Elliptic Curve Cryptography (ECC). Proses pertama yang dilakukan adalah dengan menentukan kurva elips yang akan digunakan dan bilangan pemodulo (bilangan prima) N. kemudian, menentukan titik awal (A) titik A terletak pada kurva. Selanjutnya, menentukan satu bilangan random integer (Ks). Setelah itu menghitung nilai Kp dengan mengalikan nilai Ks dengan titik awal (A). dimana Kp juga merupakan titik pada kurva. Terakhir didapatkan nilai Ks sebagai private key dan nilai Kp sebagai public key. Selanjutnya kirimkan kunci ke penerima pesan.

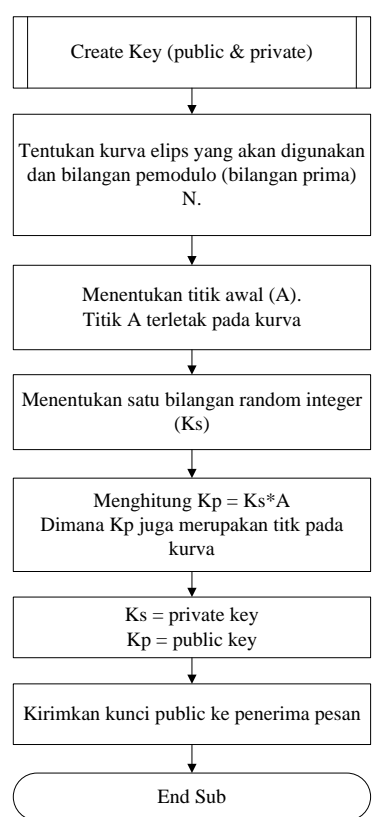

Gambar 4. Flowchart Create Key Algoritma Elliptic Curve Cryptography (ECC)

\section{HASIL DAN PEMBAHASAN}

Pengujian ini dilakukan untuk mendapatkan hasil data dari keseluruhan proses, baik proses enkripsi maupun dekripsi pada algoritma Elliptic Curve Cryptography (ECC). Untuk melakukan pengujian pada penelitian ini dengan menggunakan beberapa parameter yang digunakan. Parameter yang digunakan adalah Avalanche Effect. Pada penelitian ini telah dilakukan uji coba dengan menggunakan 25 data citra dengan cara jumlah bit terbaik dibagi dengan jumlah bit keseluruhan.

Tabel 1. Perhitungan Pengujian Sistem

\begin{tabular}{|c|c|c|c|}
\hline No & $\begin{array}{c}\text { Jumlah } \\
\text { Bit } \\
\text { Terbaik }\end{array}$ & $\begin{array}{c}\text { Jumlah Bit } \\
\text { Keseluruhan }\end{array}$ & $\begin{array}{c}\text { Avalanche } \\
\text { Effect (\%) }\end{array}$ \\
\hline 1 & 2096 & 2598 & 80.67744419 \\
\hline 2 & 4786 & 5597 & 85.51009469 \\
\hline 3 & 19018 & 25188 & 75.50420835 \\
\hline
\end{tabular}




\begin{tabular}{|c|c|c|c|}
\hline 4 & 3491 & 4125 & 84.63030303 \\
\hline 5 & 2215 & 2474 & 89.53112369 \\
\hline 6 & 24830 & 56303 & 44.10066959 \\
\hline 7 & 18509 & 23587 & 78.47119176 \\
\hline 8 & 6559 & 7056 & 92.95634921 \\
\hline 9 & 120987 & 331217 & 36.52801638 \\
\hline 10 & 27900 & 36640 & 76.14628821 \\
\hline 11 & 4302 & 5242 & 82.06791301 \\
\hline 12 & 31275 & 45413 & 68.8679453 \\
\hline 13 & 53850 & 63650 & 84.60329929 \\
\hline 14 & 27228 & 30524 & 89.20193946 \\
\hline 15 & 72275 & 103920 & 69.5486913 \\
\hline 16 & 1574 & 1876 & 83.90191898 \\
\hline 17 & 5152 & 5818 & 88.55276727 \\
\hline 18 & 4198 & 4434 & 94.67749211 \\
\hline 19 & 2629 & 2811 & 93.52543579 \\
\hline 20 & 62045 & 95020 & 65.29677963 \\
\hline 21 & 58321 & 65517 & 89.01659111 \\
\hline 22 & 12207 & 14099 & 86.58060855 \\
\hline 23 & 66300 & 79123 & 83.7935872 \\
\hline 24 & 43377 & 49865 & 86.98886995 \\
\hline 25 & 53162 & 61441 & 86.52528442 \\
\hline & Rata - rata & 79,8881925 \\
\hline
\end{tabular}

Tabel 1 adalah tabel pengujian data untuk mendapatkan nilai Avalanche Effect. Dari hasil pengujian diatas maka didapatkan nilai avalanche effect terkecil adalah 36,52801638, avalanche effect terbesar adalah 94,67749211. Dan didapatkan nilai avalanche effect rata - rata sebesar 79,8881925 . Nilai rata - rata avalanche effect yang menghasilkan persentase yang cukup besar membuktikan bahwa aplikasi berjalan dengan baik, karena semakin besar persentase yang didapatkan maka semakin baik aplikasi itu berjalan.

Avalanche Effect ini menunjukkan bahwa suatu metode cocok digunakan untuk menyelesaikan masalah yang sedang terjadi saat ini. Dengan kata lain, bahwa avalanche effect ini berfungsi untuk mengetahui apakah suatu metode sudah efektif atau belum dalam sebuah penelitian. Dari pengujian diatas dapat disimpulkan bahwa metode algoritma Elliptic Curve Cryptography (ECC) ini efektif untuk menyelesaikan masalah enkripsi dan dekripsi sebuah citra digital. Hal ini dikarenakan bahwa sebuah algoritma yang baik memiliki avalanche effect tinggi. 


\section{KESIMPULAN}

Dari hasil analisa yang telah dilakukan dapat diambil kesimpulan sebagai berikut :

Implementasi Elliptic Curve Crptograpgy cocok digunakan untuk aplikasi pada mobile phone, karena aplikasi aplikasi tersebut membutuhkan ukuran kunci dan kecepatan enkripsi dan dekripsi gambar yang cepat. Dari hasil percobaan sebanyak 25 data citra didapatkan, didapatkan nilai avalanche effect rata - rata sebesar 79,8881925. Nilai rata - rata avalanche effect yang menghasilkan persentase yang cukup besar membuktikan bahwa aplikasi berjalan dengan baik, karena semakin besar persentase yang didapatkan maka semakin baik aplikasi itu berjalan. Pada pengujian ini disarankan untuk menggunakan data dengan jumlah bit yang sama. Hal ini disebabkan, nilai Avalanche effect memburuk dikarenakan variasi ukuran yang besar. Dengan peneletian ini peneltin berharap bisa dikembangkan untuk video dan audio.

\section{DAFTAR PUSTAKA}

Damanik, Putri S E A. (2019). "Implementasi Algoritma Elliptic Curve Cryptography (ECC) Untuk Penyandian Pesan Pada Aplikasi Chatting Client Server Berbasis Desktop". Jurnal Riset Komputer. Vol. 6, No. 4. ISSN 2407 - 389X (Media Cetak).

Edy Budi Harjono Sibarani M.Kom, Prof. Dr. Muhammad Zarlis, Rahmat Widya Sembiring M. PhD. (2017)."Analisis Kriptografi Sistem Algoritma AES dan Elliptic Curve Cryptography (ECC) Untuk Keamanan Data", Info Tekjar (Jurnal Nasional Informatika dan Informasi Jaringan). Vol. 1, No. 2. e-ISSN: 2540 - 7600, p-ISSN : $2540-7597$.

Jaya Santoso Sirait, R. Rumani M., Marisa W. Paryanto. (2017). "Implementasi Kriptosystem menggunakan metode algoritma ECC dengan fungsi MD5 pada sistem database ticketing online", e-Proceeding of Engineering. Vol. 4, No. 3.

Kadhim, Dr. Alaa. Khalaf, Sura. (2015). "New Approach for Security Chatting in Real Time", International Journal of Emerging Trends \& Teknology in Computer Science (IJETTCS). Volume 4, Issue 3. ISSN $2278-6856$.

Kolhekar, Mrs. Megha. Jadhav, Mrs. Anita. (2011). "Implementation Of Elliptic Curve Cryptography On Text And Image", International Journal oF Enterprise Computing and Business systems. ISSN (Online) $2230-8849$.

Laksana, Tri Ginanjar. (2018). "Penggunaan Algoritma ECC (Elliptic Curve Cryptography) sebagai Teknik Pengamanan Transmisi Pada Query Database", Jurnal Teknik Informatika. Institut Teknologi Telkom Purwokerto.

Nawagusti, Vera Apriliani. (2018). "A Review on Elliptic Curve Cryptography and Variant", International Research Journal of engineering a technology (IRJET). Vol.05 Issue : 05.

Surfina Adilah, R. Rumani M. Marisa W. Paryasto (2017). "Implementasi Kriptosystem menggunakan metode algoritma ECC dengan fungsi hash SHA -256 pada sistem tecketing online", e-Proceeding of Engineering. Vol. 4, No. 3. 